06

\title{
Морфология и состав дефектированных массивов ниобиевых оксидных неоднородностей, сформированных анодированием двуслойной системы Al/Nb
}

\author{
(ㄱ А.Н. Плиговка, ${ }^{1}$ П.А. Юнин, ${ }^{2}$ А.В. Гога, ${ }^{1}$ С.А. Королев, ${ }^{2}$ Г.Г. Горох, ${ }^{1}$ Е.В. Скороходов ${ }^{2}$ \\ ${ }^{1}$ Белорусский государственный университет инорорматики и радиоэлектроники, \\ 220013 Минск, Беларусь \\ ${ }^{2}$ Институт фризики микроструктур РАН, \\ 603087 Нижний Новгород, Россия \\ e-mail: pligovka@bsuir.by
}

Поступило в Редакцию 28 апреля 2020 г.

В окончательной редакции 28 апреля 2020 г.

Принято к публикации 28 апреля 2020 г.

Работа посвящена рентгеноструктурному исследованию дефектированных массивов ниобиевых оксидных неоднородностей $(\mathrm{HOH})$ и наностолбиков оксида ниобия, сформированных электрохимическим анодированием. Полученные результаты позволили сделать предположение о вероятностном наличии значительного количества $\mathrm{NbO}, \mathrm{NbO}_{0.7}, \mathrm{Nb}_{2} \mathrm{O}_{5}$ и небольшого количества $\mathrm{NbO}_{2}$, и $\mathrm{Al}$ в составе дефектированных $\mathrm{HOH}$ и присутствие всех перечисленных веществ в составе наностолбиков оксида ниобия кроме $\mathrm{NbO}_{0.7}$, но в меньших количествах. Сравнительный анализ состава НОН и наностолбиков позволяет выделить, вероятно, значительное количество $\mathrm{Nb}_{0.94} \mathrm{O}_{0.06}, \mathrm{Nb}_{6} \mathrm{O}$ в дефектированных наностолбиках, чего не было обнаружено y $\mathrm{HOH}$.

Ключевые слова: анодный оксид алюминия, электрохимическое анодирование, оксид ниобия, наностолбики оксида ниобия, рентгенофазовый анализ.

DOI: 10.21883/JTF.2020.11.49974.149-20

\section{Введение}

Исследование процессов электрохимического анодного окисления (анодирования) вентильных металлов через поры анодного оксида алюминия (AOA) весьма актуально, так как анодирование позволяет создавать массивы равномерно гексагонально-упакованных наноструктурированных оксидных неоднородностей, морфологией, составом и физическими свойствами которых можно управлять, изменяя режимы анодирования [1-5]. Реанодирование таких неоднородностей приводит к формированию полноценных наностолбиков оксида ниобия [6]. Подобные массивы наностолбиков можно формировать также из анодного оксида тантала, гафния и вольфрама [7-9]. Исследования показали [10], что ниобиевые оксидные неоднородности $(\mathrm{HOH})$ обладают различной морфологией в отличие, например, от неоднородностей оксида тантала, которые во всех установленных ранее режимах анодирования имеют одинаковую шарообразную форму [2]. Из работы [11] видно, что НОН отличаются не только размером, но также формой и характером расположения. Основные работы [2,6] на эту тему, посвящены исследованию морфологии и состава столбиков оксида ниобия, при этом состав самих $\mathrm{HOH}$ мало изучен. Результаты исследования НОН методом рентгеновской фотоэлектронной спектроскопии (РФЭС) представлены в работе [11]. НОН формировали анодированием в $0.8 \mathrm{M}$ водном растворе винной кислоты при напряжении формовки $200 \mathrm{~V}$. Форма таких НОН была кубкообразной, что является типичным для данного режима [10]. Исследование показало присутствие $\mathrm{Nb}, \mathrm{O}$, $\mathrm{Al}$ и $\mathrm{C}$ в составе рассмотренных образований. Глубоким профилированием были определены пики $\mathrm{Nb} 3 d, \mathrm{Al} 2 p$, $\mathrm{O} 1 s$ и C $1 s$. Пик углеерода исчезал сразу после начала распыления $\mathrm{Ar}^{+}$, что указывает на отсутствие включенных частиц, содержащих углерод, в составе НОН. $\mathrm{B}$ начале распыления $\mathrm{Ar}^{+}$, измеренный спектр $\mathrm{Nb} 3 d$ состоял из двойного пика $\left(3 d_{5 / 2}\right.$ и $\left.3 d_{3 / 2}\right)$, соответствующего состоянию $\mathrm{Nb}^{5+}$. Через $3 \mathrm{~min}$ на низкоэнергетическом крае пика $\mathrm{Nb}_{2} \mathrm{O}_{5}$ появлялось плечо, которое затем развивалось в дополнительный двойной пик с энергиями связи 201.5 и $204.3 \mathrm{eV}$, которые являются типичными энергиями связи для электронов $3 d_{5 / 2}$ и $3 d_{3 / 2}$ в состоянии $\mathrm{Nb}^{0}$. Во время распыления положение пика металлического ниобия практически не изменялось, а его интенсивность увеличивалась, достигая максимума при времени распыления, превышающем $100 \mathrm{~min}$. Два пика существуют одновременно, пока пик оксида ниобия V не становился неясным (10 min); однако плечо на границе высоких энергий пика металлического ниобия оставалось в течение $20 \mathrm{~min}$ распыления $\mathrm{Ar}^{+}$. Это указывает на переход от стехиометрического $\mathrm{Nb}_{2} \mathrm{O}_{5}$ на поверхности к металлическому ниобию с одновременным существованием как металла, так и оксида ниобия V во время распыления. Описанная эволюция двух пиков также предполагала наличие субоксидов ниобия 

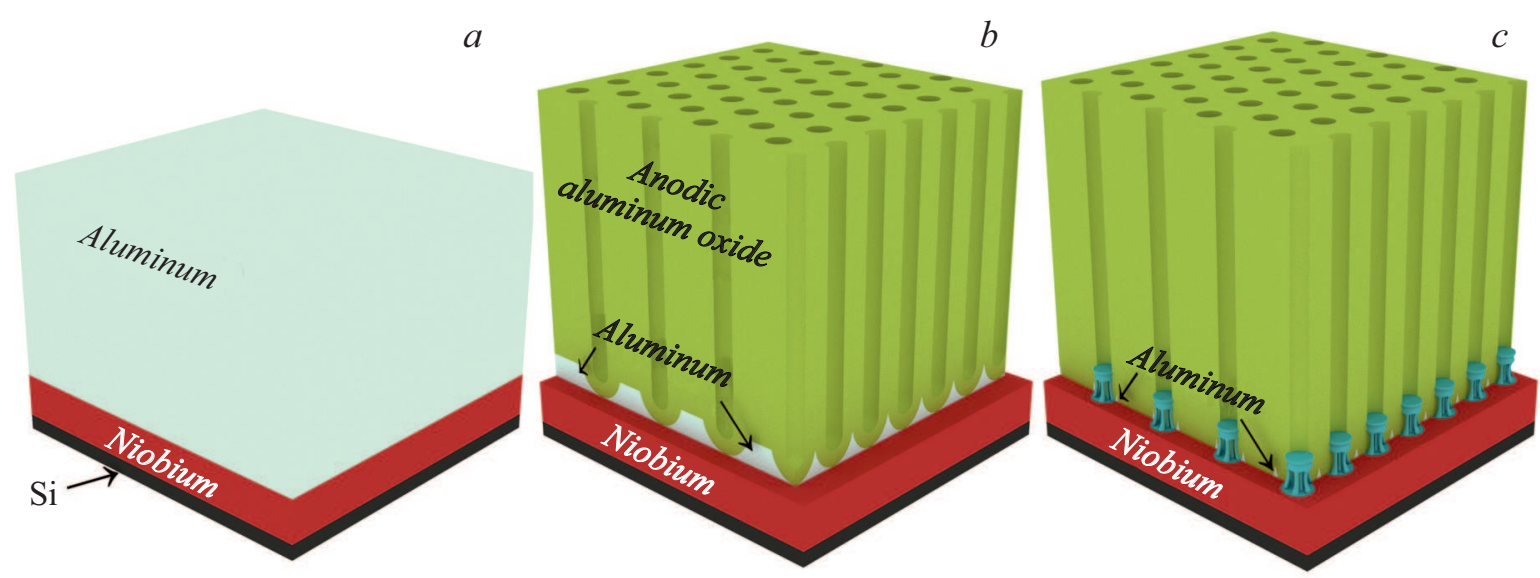

$d$
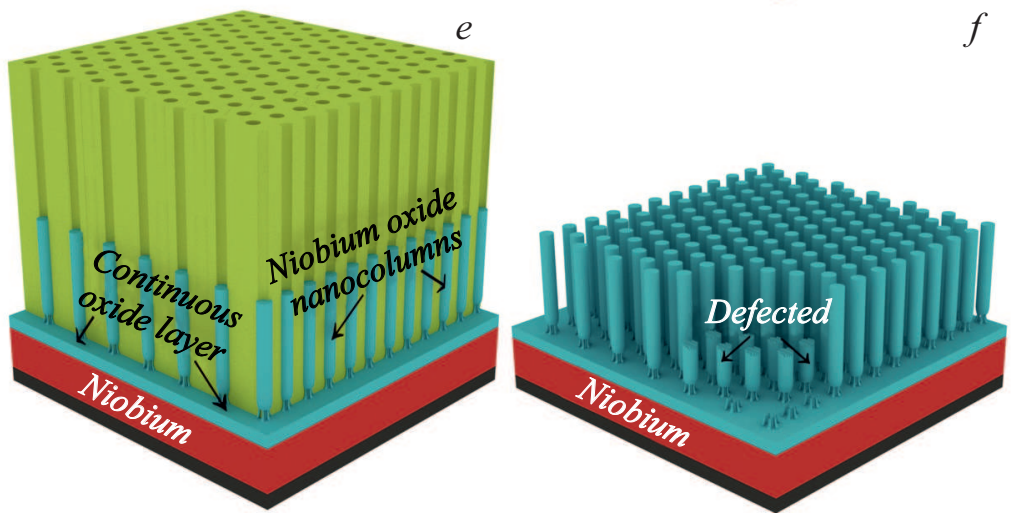

Рис. 1. Принципиальная схема, показывающая основные этапы формирования ниобиевых оксидных неоднородностей и наностолбиков анодированием двухслойной системы $\mathrm{Al} / \mathrm{Nb}$ на $\mathrm{Si}$-подложке: $a-$ распыление двухслойной системы $\mathrm{Al} / \mathrm{Nb}$ на $\mathrm{Si}$ подложку; $b$ - анодирование $\mathrm{Al}$ с образованием пористого анодного оксида алюминия (AОА); $c$ - анодирование подслоя $\mathrm{Nb}$ через поры АОА; $d$ - удаление пористого АОА химическим травлением и механическое дефектирование ниобиевых оксидных неоднородностей; $e-$ ре-анодирование подслоя $\mathrm{Nb}$ через поры АОА до более высокого напряжения; $f$ - удаление пористого АОА химическим травлением и механическое дефектирование наностолбиков оксида ниобия. $c$ - ниобиевые оксидные неоднородности $(\mathrm{NON})$, сформированные анодированием в водном $0.4 \mathrm{M}$ растворе $\mathrm{H}_{3} \mathrm{PO}_{4}$ при напряжении $100 \mathrm{~V} ; f$ - наностолбики оксида ниобия, сформированные анодированием в водном $0.4 \mathrm{M}$ растворе $\mathrm{C}_{2} \mathrm{H}_{2} \mathrm{O}_{4}$ при напряжении $37 \mathrm{~V}$ и ре-анодированные в растворе $0.5 \mathrm{M}$ $\mathrm{H}_{3} \mathrm{BO}_{3}$ и $0.05 \mathrm{M} \mathrm{Na}_{2} \mathrm{~B}_{4} \mathrm{O}_{7}$ до напряжения $190 \mathrm{~V}$.

в составе пленки. Кроме того, появление и эволюция пика металлического ниобия предполагали присутствие неокисленного металлического ниобия вокруг оснований НОН. Относительно медленное увеличение интенсивности пика $\mathrm{Nb}^{0}$ в начале распыления $\mathrm{Ar}^{+}$могло быть объяснено покрытием пленки ниобия остаточным алюминием, который одновременно распылялся пучком $\mathrm{Ar}^{+}$. Начальный спектр распыления состоял из двух различных симметричных пиков: первый при $72.2 \mathrm{eV}$, связанный с состоянием $\mathrm{Al}^{0}$ (более высокая интенсивность), и второй с $74.8 \mathrm{eV}$ (более низкая интенсивность), который относится к состоянию $\mathrm{Al}^{3+}$. После первого цикла распыления интенсивность обоих пиков увеличивалось в одинаковой степени, но затем в паре начинал доминировать пик $\mathrm{Al}^{0}$. Пик $\mathrm{Al}^{3+}$ резко ослабевал и полностью исчезал после $20 \mathrm{~min}$ распыления. И наоборот, пик металлического алюминия усиливался со временем распыления и после достижения максимума постепенно уменьшался, тем не менее, не исчезая совсем в течение 180 min после распыления $\mathrm{Ar}^{+}$. Очевидно, что сильный и длинный профилированный пик $\mathrm{Al}^{0}$ обусловлен большим количеством металлического алюминия, окружающего НОН. Относительно короткий профиль глубины для пика $\mathrm{Al}^{3+}$ подразумевает, что оксид алюминия находился только во внешней части НОН (скорее всего, в верхушках - рис. 1). Измеренный спектр О $1 s$ образца, не обработанного $\mathrm{Ar}^{+}$, состоял из симметричного пика с энергией $531.8 \mathrm{eV}$, который мог быть связан с кислородом, связанным в АОА. Во время распыления $\mathrm{Ar}^{+}$ положение пика О $1 s$ постепенно смещалось в сторону более низких энергий, и после $18 \mathrm{~min}$ пик регистрировался при $530.7 \mathrm{eV}$, что характеризовало этот пик как соответствующий кислороду, связанному в оксиде ниобия. Это хорошо соответствует профилю глубины пика $\mathrm{Al}^{3+}$, идентифицированного в составе $\mathrm{HOH}$, и подтверждает предположение о внешнем расположении алюминия в структуре верхушки НОН. Таким образом, анализ литературных данных позволяет оценить поверхностный состав НОН, однако в литературных источниках не было найдено информации о внутреннем составе 
НОН. Такие исследования можно провести, одновременно использовав два приема: нарушив целостность $\mathrm{HOH}$, дефектировав их с одной стороны и применив рентгенодифракционный метод исследования [12] с другой.

Целью настоящей работы явилось исследование методом рентгенофазового анализа (РФА) [13,14] состава механически дефектированных массивов ниобиевых оксидных неоднородностей, сформированных методом электрохимического анодирования двухслойной системы $\mathrm{Al} / \mathrm{Nb}$.

\section{1. Экспериментальная часть}

Процесс формирования НОН представлен на рис. 1. Исходные образцы представляли собой $100 \mathrm{~mm}$ кремниевые пластины ( $n$-типа, $4 \Omega \cdot \mathrm{cm})$, на которые методом магнетронного распыления наносили двухслойные системы $\mathrm{Al} / \mathrm{Nb}(1500 / 300 \mathrm{~nm})$, как показано на рис. $1, a$. Предварительно перед процессом анодирования пластину $\mathrm{Si}$ разрезали на образцы площадью $3 \times 3 \mathrm{~cm}$. Непосредственно сам процесс анодирования проводили в цилиндрической двухэлектродной ячейке из политетрафторэтилена (ПТФЭ). Ячейка для анодирования состояла из электролитической ванны со встроенным анодом, которая прижимала образец кремниевой пластины с напыленными металлами, - экспериментальный образец, к основанию ячейки, тем самым исключая менисковый эффект и паразитное окисление кремния. Катод, располагавшийся в электролите, был выполнен из нержавеющей стали. Экспериментальный образец был индивидуально размещен в анодной ячейке и прижат со стороны алюминия кольцом ПТФЭ, так что круглая область площадью $2.83 \mathrm{~cm}^{2}$ находилась в контакте с анодирующим раствором, в то время как обратная кремниевая сторона была полностью изолирована от электролита. Сначала анодировали алюминий до полного его прокисления, как показано на рис. $1, b$, в $0.4 \mathrm{M}$ водном растворе $\mathrm{H}_{3} \mathrm{PO}_{4}$ при напряжении $100 \mathrm{~V}$. Анодирование проводили в потенциостатическом режиме, о достижении барьерным слоем АОА подслоя ниобия свидетельствовало начало падения тока на кинетической зависимости. На следующем этапе в процессе плавного падения анодного тока происходил процесс анодирования подслоя ниобия через поры AOA до образования $\mathrm{HOH}$, как показано на рис. 1, c. Для проведения сравнительного анализа состава были сформированы наностолбики анодного оксида ниобия в $0.4 \mathrm{M}$ водном растворе щавелевой кислоты при напряжении $37 \mathrm{~V}$ с последующим высоковольтным ре-анодированием до напряжения $190 \mathrm{~V}$ в растворе $0.5 \mathrm{M} \mathrm{H}_{3} \mathrm{BO}_{3}$ и $0.05 \mathrm{M}$ $\mathrm{Na}_{2} \mathrm{~B}_{4} \mathrm{O}_{7}$, как показано на рис. $1, e$. Процесс формирования наностолбиков данного типа подробно описан в работе [6]. Режимы анодирования задавали с помощью источника питания Keysight N5752A, регистрацию и мониторинг in situ параметров проводили с помощью Keysight 34470A. В процессе анодирования поддержива- ли комнатную температуру $\left(23^{\circ} \mathrm{C}\right)$ с точностью $\pm 1^{\circ} \mathrm{C}$. Удаление пористого АОА проводили в 50\% водном растворе $\mathrm{H}_{3} \mathrm{PO}_{4}$ при температуре $50^{\circ} \mathrm{C}$ в течение $30 \mathrm{~min}$.

Исследование морфологии проводили методом сканирующей электронной микроскопии (СЭМ) на электронном микроскопе Carl Zeiss Supra 50VP. Фазовый состав исследовали с помощью рентгеновского дифрактометра Bruker D8 Discover. Анализ осуществлялись тета-2тета сканированием с использованием позиционно-чувствительного детектора LynxEye, излучение $-\mathrm{Cu} K_{\alpha}$.

Рентгенографические методы анализа широко используются для изучения структуры, состава и свойств различных материалов. Широкому распространению рентгенографического анализа способствуют его объективность, универсальность, быстрота многих его методов, точность и возможность решения разнообразных задач, часто не доступных для других методов исследования. С помощью рентгенографического анализа, в частности, исследуют: качественный и количественный минералогический и фазовый состав материалов (РФА), являясь во многих случаях единственным методом контроля фазового состава. РФА основан на том, что каждая кристаллическая фаза дает индивидуальную, неповторимую картину расположения дифракционных максимумов и их интенсивностей [15-18]. Для изучения внутреннего состава НОН и наностолбиков проводили механическое дефектирование -- целенаправленное частичное разрушение наноструктур для обеспечения гарантированного доступа детектирующего излучения к их внутренней структуре (рис. $1, d, f)$. В определенной мере такой прием являлся, вероятно, избыточным, поскольку рентгеновское излучение обладает высокой проникающей способностью. Именно эти обстоятельства обусловили применение метода исследования, основанного на дифракции рентгеновских лучей [19], позволяющего достоверным, простым, недорогим и доступным способом проанализировать образцы НОН, получая интегральную картину их фазового состава на большую глубину [14].

\section{2. Результаты и их обсуждение}

На рис. 2, а представлено СЭМ-изображение поверхности под углом $\mathrm{HOH}$, сформированных в $0.4 \mathrm{M}$ водном растворе $\mathrm{H}_{3} \mathrm{PO}_{4}$ при напряжении $100 \mathrm{~V}$ и с удаленным пористым АОА. Из рис. 2, $a$ видно, что вся поверхность равномерно покрыта механически дефектированными НОН одинаковой формы, размера и периодичности. Все $\mathrm{HOH}$ состоят из основания (bottom), находящегося в пленке $\mathrm{Nb}$, верхушки (top), располагавшейся в поре AОА до его удаления, и стеблей (stems), соединяющих основание и верхушку, располагавшуюся в барьерном слое АОА до его удаления. Описанные $\mathrm{HOH}$ обладают уникальными морфологическими особенностями, которые отличают их от других типов $\mathrm{HOH}$, представленных в работах $[11,12]$ : во-первых, стебли НОН расположены 


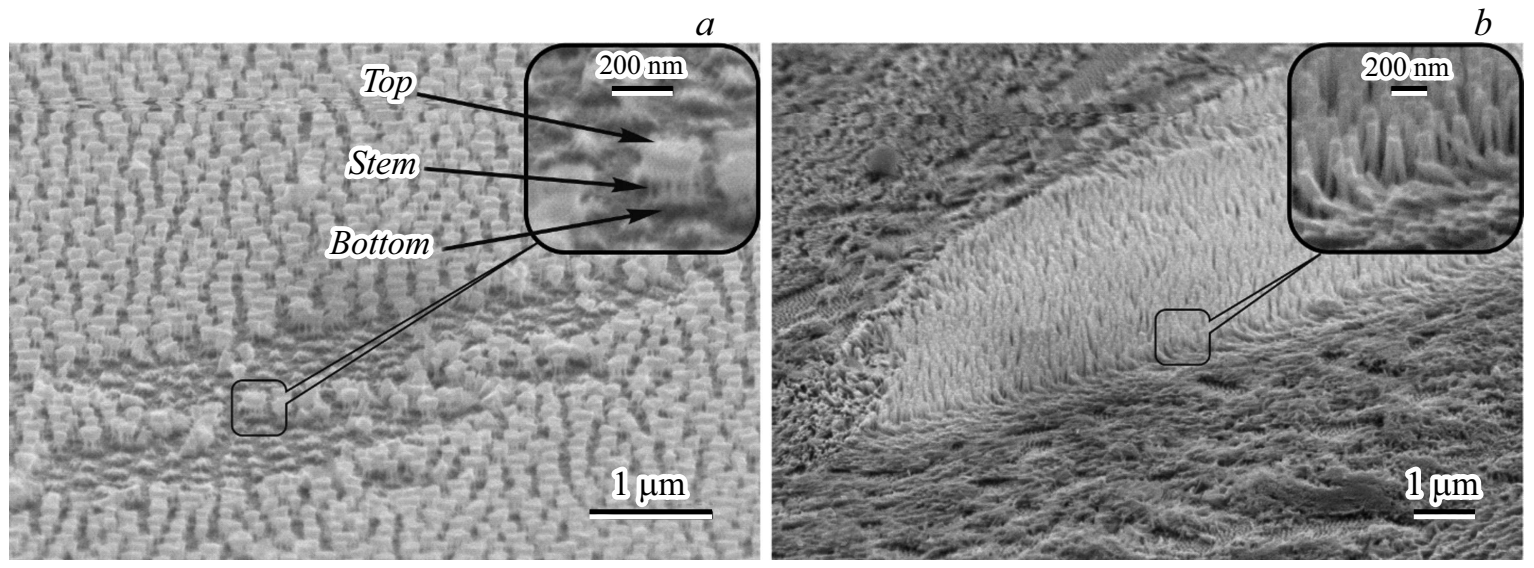

Рис. 2. Сканирующая электронная микроскопия: $a$ - дефектированных ниобиевых оксидных неоднородностей, сформированных анодированием двухслойной системы $\mathrm{Al} / \mathrm{Nb}$ в водном $0.4 \mathrm{M}$ растворе $\mathrm{H}_{3} \mathrm{PO}_{4}$ при напряжении $100 \mathrm{~V}$ и $b-$ дефектированных

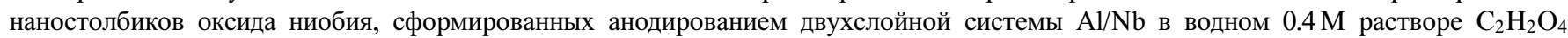
при напряжении $37 \mathrm{~V}$ и ре-анодированных в растворе $0.5 \mathrm{M} \mathrm{H}_{3} \mathrm{BO}_{3}$ и $0.05 \mathrm{M} \mathrm{Na}_{2} \mathrm{~B}_{4} \mathrm{O}_{7}$ до напряжения $190 \mathrm{~V}$. На изображениях представлены наноструктуры после удаления пористого анодного оксида алюминия.
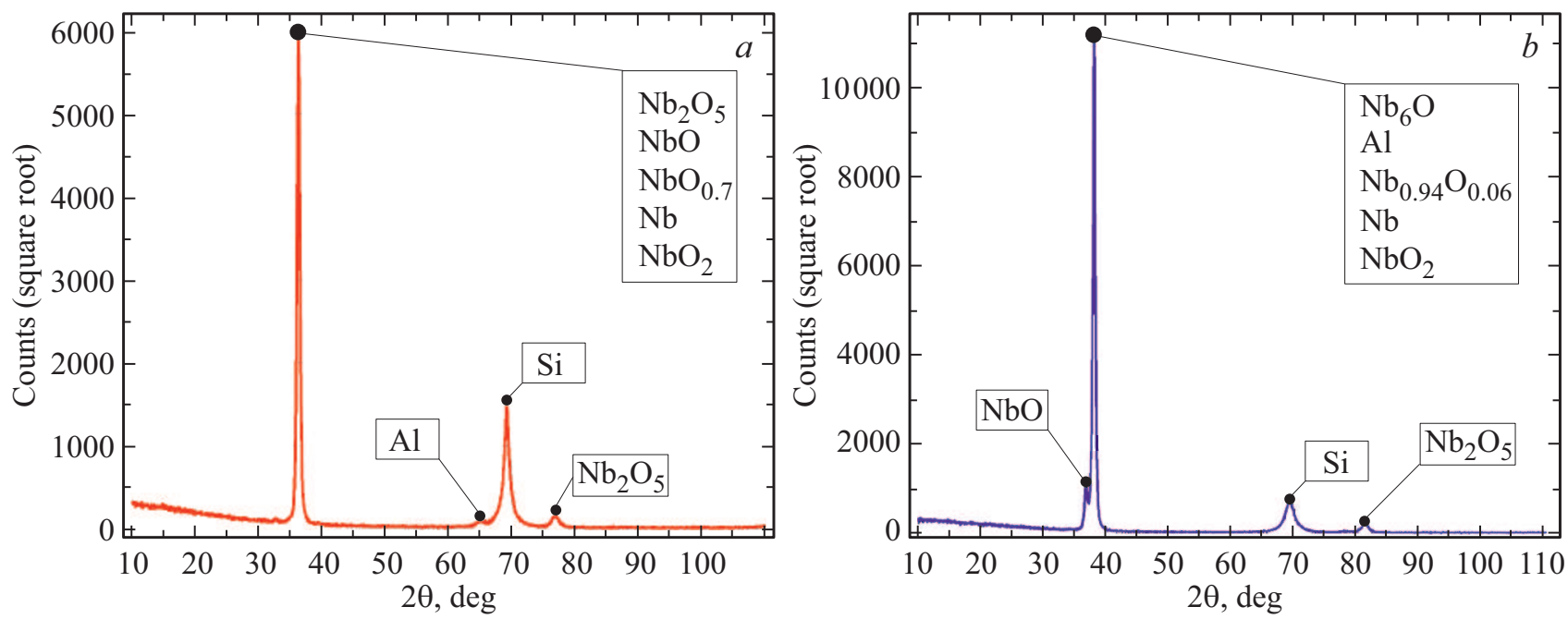

Рис. 3. Рентгеноструктурный анализ: $a$ - дефектированных ниобиевых оксидных неоднородностей, сформированных анодированием двухслойной системы $\mathrm{Al} / \mathrm{Nb}$ в водном $0.4 \mathrm{M}$ растворе $\mathrm{H}_{3} \mathrm{PO}_{4}$ при напряжении $100 \mathrm{~V}$, и $b$ - дефектированных наностолбиков оксида ниобия, сформированных анодированием двухслойной системы $\mathrm{Al} / \mathrm{Nb}$ в водном $0.4 \mathrm{M}$ растворе $\mathrm{C}_{2} \mathrm{H}_{2} \mathrm{O}_{4}$ при напряжении $37 \mathrm{~V}$ и ре-анодированных в растворе $0.5 \mathrm{M} \mathrm{H}_{3} \mathrm{BO}_{3}$ и $0.05 \mathrm{M} \mathrm{Na}_{2} \mathrm{~B}_{4} \mathrm{O}_{7}$ до напряжения $190 \mathrm{~V}$.

на значительном равноудаленном расстоянии друг от друга; во-вторых, диаметр НОН соизмерим с их высотой. Исследования, проведенные ранее, показывают [10,11], что все другие известные условия формирования не позволяют получить $\mathrm{HOH} \mathrm{с} \mathrm{такими} \mathrm{морфологическими}$ особенностями.

На рис. 2,b представлено СЭМ-изображение поверхности под углом наностолбиков оксида ниобия, сформированных в $0.4 \mathrm{M}$ водном растворе $\mathrm{C}_{2} \mathrm{H}_{2} \mathrm{O}_{4}$ при напряжении $37 \mathrm{~V}$ и последующем ре-анодировании до напряжения $190 \mathrm{~V}$ в растворе $0.5 \mathrm{M} \mathrm{H}_{3} \mathrm{BO}_{3}$ и $0.05 \mathrm{M} \mathrm{Na}_{2} \mathrm{~B}_{4} \mathrm{O}_{7}$. Перед СЭМ-наблюдениями проводили удаление пористого АОА. Из рис. 2, $b$ видно, что вся поверхность равномерно покрыта механически дефектированными наностолбиками одинаковой формы и размерами. Форма столбиков полностью соответствует описанной ранее в работе [6].

На рис. 3, $а$ представлены результаты РФА дефектированных НОН. Предварительно проводилось полное удаление пористого АОА. Проведенные исследования показали наличие одного сильного пика вблизи $36^{\circ}$, который может быть отнесен к сильно текстурированным фазам $\mathrm{NbO}, \mathrm{NbO}_{0.7}, \mathrm{Nb}_{2} \mathrm{O}_{5}$. Существование $\mathrm{Nb}_{2} \mathrm{O}_{5}$ в НОН было показано ранее в работах [1,2]. Однако присутствие оксидов $\mathrm{NbO}_{0.7}$ и $\mathrm{NbO}$ в предыдущей работе [11], где был исследован состав НОН методом РФС, обнаружено не было. Кроме этих фаз, связанных с сильными пиками на дифрактограммах, в $\mathrm{HOH}$ 
присутствуют слабо текстурированные фазы в малых количествах: $\mathrm{NbO}_{2}, \mathrm{Nb}_{4} \mathrm{O}_{5}$ и Al. Наличие $\mathrm{Al}$ может быть связано с неполным его удалением после химического растворения пористого АОА, а также с присутствием его в верхушке НОН. Как ранее показано [2], попадание алюминия в верхушки $\mathrm{HOH}$ происходит в процессе высоковольтного ре-анодирования, когда внешний разреженный дефектный слой поры АОА смешивается с текучим анодным оксидом ниобия, заполняющим пору. Однако, как можно предположить на основании представленных результатов, алюминий с высокой степенью вероятности появляется в верхушках $\mathrm{HOH}$ и на стадии анодирования. Присутствие $\mathrm{NbO}_{2}$ в спектре $\mathrm{HOH}$ также довольно типично, что также было показано ранее [2], сплошной оксидный слой наностолбиков, который развивается из основания $\mathrm{HOH}$ полностью состоит из $\mathrm{NbO}_{2}$. Среди указанных фаз обнаружено небольшое количество $\mathrm{Nb}_{4} \mathrm{O}_{5}$, присутствие которого обнаружено впервые. Как видно из рис. 2, $a$, дефектирование $\mathrm{HOH}$ преимущественно приводит к отделению верхушек НОН от их оснований через разрушения стеблей. И вероятностные результаты появления на спектрах новых оксидных форм морфологически могут располагаться только на сломах стеблей $\mathrm{HOH}$.

На рис. 3, $b$ представлены результаты рентгеноструктурного анализа дефектированных наностолбиков анодного оксида ниобия. Перед анализом проводилось полное удаление пористого АОА. На представленном спектре пик $36^{\circ}$ также присутствует, но с более слабой интенсивностью. Это указывает также о вероятном наличии оксидов ниобия, свойственных $\mathrm{HOH}$ : $\mathrm{NbO}, \mathrm{Nb}_{2} \mathrm{O}_{5}$, $\mathrm{NbO}_{0.7}, \mathrm{NbO}_{2}$, но в меньших количествах. При этом возникает сильный пик на $38-39^{\circ}$. Он может быть связан с $\mathrm{Nb}_{0.94} \mathrm{O}_{0.06}, \mathrm{Nb}_{6} \mathrm{O}$, что является типичным для ре-анодированных наноструктур, как показано в работах [2,10]. По причине того, что верхушка столбика гипертрофирована и имеет вытянутую форму, в процессе дефектирования могло произойти ее разрушение в любой части, не только у основания, как для $\mathrm{HOH}$, поэтому однозначно сделать вывод о том, что появление новых оксидов связано с их наличием в стеблях или в гипертрофированных верхушках, не представляется возможным.

\section{Заключение}

Подводя итоги, можно сделать следующие выводы. Состав и морфология дефектированных $\mathrm{HOH}$, формируемых анодированием, значительно отличаются по морфологии и составу от столбиков оксида ниобия, которые образуются реанодированием НОН. В первом случае присутствует значительно количество $\mathrm{Nb}_{2} \mathrm{O}_{5}$, $\mathrm{NbO}$ и $\mathrm{NbO}_{0.7}$, а также в небольших количествах $\mathrm{NbO}_{2}$, что полностью коррелирует с литературными данными. В свою очередь, в дефектированных наностолбиках оксида ниобия обнаружено значительное количество
$\mathrm{Nb}_{0.94} \mathrm{O}_{0.06}, \mathrm{Nb}_{6} \mathrm{O}$ и в небольших количествах $\mathrm{NbO}$, $\mathrm{Nb}_{2} \mathrm{O}_{5}, \mathrm{NbO}_{0.7}, \mathrm{NbO}_{2}$, что ожидаемо подтверждается литературными данными для ре-анодированных наноструктур.

Полученные данные расширяют представления о наноструктурированных оксидах ниобия и позволяют в будущем использовать их для построения новейших приборов нелинейной оптики и наноэлектроники.

\section{Благодарности}

Авторы выражают благодарность Оргкомитету XXIV Международного симпозиума „Нанофизика и наноэлектроника“ за возможность представить результаты исследований. Авторы благодарят У. Туровец из Белорусского государственного университета информатики и радиоэлектроники (БГУИР) за помощь с компьютерным моделированием схемы формирования ниобиевых оксидных неоднородностей и доцента БГУИР А.А. Позняка за ценные обсуждения.

\section{Финансирование работы}

Работа выполнена при поддержке государственной программы научных исследований Республики Беларусь „Конвергенция-2020“ (задание 3.03) и научнотехнической программы Союзного государства „Технология-СГ“ (задание 2.3.2.1) с использованием оборудования ЦКП „Физика и технологии микро- и наноструктур“ при ИФМ РАН.

\section{Конфликт интересов}

Авторы заявляют, что у них нет конфликта интересов.

\section{Список литературы}

[1] Surganov V., Gorokh G. // Symposium on Design, Test, Integration, and Packaging of MEMS/MOEMS. 2000. Vol. 4019. DOI: $10.1117 / 12.382321$

[2] Mozalev A., Vázquez R.M., Bittencourt C., Cossement D., Gispert-Guirado F., Liobel E., Habazaki H. // J. Mater. Chem. C. 2014. Vol. 2. N 24. P. 4847-4860. DOI: $10.1039 / \mathrm{c} 4 \mathrm{tc} 00349 \mathrm{~g}$

[3] Pligovka A., Lazavenka A., Zakhlebayeva A. // Proc. of the 18th Int. Conf. on Nanotechnology (IEEE-NANO). Cork, Ireland, 2018. DOI: 10.1109/NANO.2018.8626387

[4] Pligovka A., Zakhlebayeva A., Lazavenka A. // J. Phys. Conf. Ser. 2018. Vol. 987. N 1. P. 012006. DOI: $10.1088 / 1742-6596 / 987 / 1 / 012006$

[5] Плиговка А.Н., Горох Г.Г. // Сб. науч. ст. Минск: ИТМО им. А.В. Лыкова, 2014. С. 310-319.

[6] Pligovka A., Lazavenka A., Gorokh G. // IEEE Tr. Nanotechnol. 2019. Vol. 18. N 125. P. 790-797.

DOI: 10.1109/TNANO.2019.2930901

[7] Mozalev A., Smith A.J., Borodin S., Plihauka A., Hassel A.W., Sakairi M., Takahashi H. // Electrochim. Acta. 2009. Vol. 54. N 3. P. 935-945. DOI: 10.1016/j.electacta.2008.08.030 
[8] Mozalev A., Bendova M., Gispert-Guirado F., Llobet E. // Chem. Mater. 2018. Vol. 30. N 8. P. 2694-2709.

DOI: $10.1021 /$ acs.chemmater.8b00188

[9] Mozalev A., Khatko V., Bittencourt C., Hassel A.W., Gorokh G., Liobel E., Correig X. // Chem. Mater. 2008. Vol. 20. N 20. P. 6482-6493. DOI: $10.1021 / \mathrm{cm} 801481 \mathrm{z}$

[10] Горох Г.Г., Плиговка А.Н., Лозовенко А.А. // ЖТФ. 2019. T. 89. Вып. 11. С. 1747-1755. [Gorokh G.G., Pligovka A.N., Lozovenko A.A. // Tech. Phys. 2019. Vol. 64. N 11. P. 16571665. DOI: $10.1134 / \mathrm{S} 1063784219110124]$

[11] Mozalev A., Sakairi M., Saeki I., Takahashi H. // Electrochim. Acta. 2003. Vol. 48. N 20. P. 3155-3170.

DOI: $10.1016 / \mathrm{S} 0013-4686(03) 00345-1$

[12] Порай-Кошии, М.А. Основы структурного анализа химических соединений: Учеб. пособие. М.: Высш. школа, 1989. C. 192.

[13] Уманский Я.С., Чириков Н.В. Физическая энциклопедия. М.: Большая российская энциклопедия, 1994. Т. 4. С. $377-$ 378.

[14] Крылов В.Д. Химическая энциклопедия. М.: Большая российская энциклопедия, 1995. Т. 4. С. 242-243.

[15] Горшков В.С., Тимашев В.В., Савельев В.Г. Методы физико-химического анализа вяжущих веществ: Учеб. пособие. М.: Высш. школа, 1981. С. 335.

[16] Жарский И.М., Новиков Г.И. Физические методы исследования в неорганической химии: Учеб. пособие для хим. и хим.-технол. вузов. М.: Высш. школа, 1988. С. 271.

[17] Сайбуллин Р.С. Физикохимия неорганических полимерных и композиционных материалов. М.: Химия, 1990. C. 240.

[18] Бобкова Н.М. Физическая химия тугоплавких неметаллических и силикатных материалов: учебник. Минск: Высш. школа, 2007. С. 301.

[19] Колпаков А.В. Физическая энциклопедия. М.: Советская энциклопедия, 1988. Т. 1. С. 671-674. 